\title{
$\mathrm{UCC}$ 서비스 사이트의 정보품질 평가 모델 개발
}

\author{
강소라 ${ }^{1}$, 김유정 $^{*}$, 이현주 ${ }^{1}$, 문윤지 $^{1}$, 김우곤 $^{2}$ \\ ${ }^{1}$ 호서대학교 디지털비즈니스학부 \\ ${ }^{2}$ College of Business, Florida State University
}

\section{An Evaluation Model of Information Quality of UCC Service Site}

\author{
Sora Kang ${ }^{1 *}$, Yoo-Jung Kim ${ }^{1 *}$, HyunJu Lee ${ }^{1}$, Yoon Ji Moon ${ }^{1}$ and Woody Kim ${ }^{2}$ \\ ${ }^{1}$ Division of Digital Business, Hoseo University \\ ${ }^{2}$ College of Business, Florida State University
}

\begin{abstract}
요 약 본 연구는 $\mathrm{UCC}$ 의 서비스 품질 중에서 특히 정보품질을 측정하기에 적합한 모델을 개발하기 위해 정보 품질 측면에서 사용자의 참여, 개방 및 공유의 특성을 반영할 수 있는 측정요인들이 검증되었다. 연구방법은 기존 문헌연 구만으로 정보품질 요소들을 도출될 수 없기 때문에 본 연구에서는 Focus Group Interview와 전문가 인터뷰를 통한 질적 연구 방법론에 기초해서 정보 품질 면에서의 UCC e-SQ 요소, 하위 요소와 세부 측정항목을 도출하였다. 그리고 도출된 항목은 다시 역으로 web 2.0 관련 선행연구에서 실제 그 중요성이 논의되고 있는지 다시 한번 광범위한 문헌 연구를 통해 검토되었다. 마지막으로 확정된 설문 문항의 타당성과 신뢰성을 검증하기 위해 본 연구에서는 한국과 미 국 대학생 집단을 대상으로 총 221 부의 설문지를 수집하여 구조 방정식 모형을 이용하여 본 연구가 제안한 UCC $\mathrm{e}-\mathrm{SQ}$ 측정모델을 검증하였다.

연구결과, 초기 정보품질은 3 가지 1차 요인 (정보성, 신뢰성, 흥미성), 6 가지 2차 요인 (풍부성, 유용성, 신뢰성, 피드 백, 흥미성, 기발성)의 39 개 항목이 나타났는데, 최종적으로는 정보충분성(3항목), 정보피드백(3항목), 최신성(4항목), 정보활용성(7항목), 정확성(3항목), 정보신뢰성(4항목), 정보흥미성(8 항목)으로 나타났다. 이상의 연구결과를 바탕으로 연구의 논의와 시사점을 제시하였다.
\end{abstract}

\begin{abstract}
This research was conducted to develop a model appropriate for the measurement of information quality of UCC service site. The evaluation factors that reflect more improvement of the information utilization capability were verified. Enhancement of information utilization capability can control greater amount of information among the users and site companies, and among users. Therefore, Wikipedia, for example, provides a Web 2.0 based information quality that is more advanced than Web 1.0 by allowing effective control of information among the users. This type of information quality presents 'information reliability' and 'information stability' as evaluation factors added to the factors such as 'information sufficiency' and 'information usability.'Information reliability and information stability are essential factors that need to conduct an evaluation in the Web 2.0 environment that can distribute greater number of information in the environment where all the users serve as participants. Moreover, 'interesting information' and 'originality of information' suggests that information itself should include the attributes that can attract the attention of users, due to the nature of the Attention Economics, which points out one of the Web 2.0 phenomenon that the number of information consumers is smaller than thatof information suppliers.
\end{abstract}

Key Words : UCC Service Site, Information Quality, Web 2.0, e-SQ

본 논문은 2007년도 정부재원(교육인적자원부학술연구조성사업비)으로 한국학술진흥재단의 지원을받아 연구되었습니다. (KRF-2007-321-B00049)

*교신저자 : 김유정(faith@hoseo.edu)

접수일 10 년 06 월 19 일 수정일 10 년 07 월 12 일 게재확정일 10 년 08 월 10 일 


\section{1. 서론}

Web 2.0은 2003 2004 년 이후 변화한 World Wide $\mathrm{Web}$ 의 다양한 혁신적인 현상들을 포함하는 단어로 등장 했다. Web 2.0 의 가장 대표적인 특징은 일반 사용자의 창 조, 사용자 간 사회적 연계에 의한 컨텐츠의 공유, 그리고 인터넷 공간을 통한 컨텐츠와 기술의 개방이라고 볼 수 있다. 이 같은 Web 2.0 의 고유한 세 가지 특징을 명백히 보여주는 Web 2.0 features 가운데 하나는 UCC(User-Created-Contents)이다[6].

최근 폭발적인UCC 컨텐츠 사용자의 증가와 더불어 UCC 서비스가 다양한 형태로(e.g., blog, wikis, social bookmarking, multimedia sharing, or podcasting, etc.) 나 타남에 따라 성공적인 UCC 서비스 기업이라면 갖추어야 할 핵심적인 서비스 품질 요소를 파악하는 것이 급선무 가 되었다. Pareto의 법칙에서 제외된 $80 \%$ 의 소수가 $\mathrm{Web}$ 2.0 등장 이후 사용자 간 활발한 커뮤니케이션과 상호작 용에 의해 가치 창출 그룹으로서의 잠재력이 높아짐을 시사하는 Long Tail 현상이 보여주듯이[6], UCC 서비스 에 대한 핵심적인 품질 요소에 대한 탐색과 서비스 개선 에 대한 노력은 궁극적으로 사용자 참여를 극대화하고 그들이 생산해낸 컨텐츠를 통해 의견을 직접적으로 수용 함으로써 향후 기업 활동에 대다수 사용자를 포함시킬 수 있는 경쟁우위 전략으로서의 역할도 수행할 수 있다 고 보여진다.

하지만 Web 1.0 기반 서비스 기업의 e-SQ에 대한 연구 도 여전히 부족한 현실에서 $[4,18,22,24,31] \mathrm{Web} 2.0$ 기 반의 UCC 서비스에 대한 e-SQ 연구는 더욱 부족할 수 밖에 없다. e-SQ의 초기 모델은 웹 사이트 디자인 평가에 기초하며 $[8,10,14,15,17,25,27,29,32,33,36]$, 이후 전자 상거래 활성화와 더불어 발전된 e-SQ 모델은 웹 사 이트의 기술적 측면과 서비스 요소를 모두 포함하고 있 지만 상품이나 서비스를 거래하는 $\mathrm{B} 2 \mathrm{C}$ 사이트라는 특성 상 온라인에서 교환되는 정보의 측면은 간과되고있다. 즉, Web 1.0 위주의 e-SQ 모델은 마케팅 관점에서 서비 스 품질에 초점을 두고 개발된 전통적인 서비스 품질 모 델을 인터넷 서비스 분야로 옮겨와 $\mathrm{B} 2 \mathrm{C}$ 에 적용한 것이 기 때문에 Web 2.0 의 키워드인 정보의 공유와 개방, 사용 자의 직접 참여와 같은 특성을 반영하는 데에는 한계가 있다.

그러나 $\mathrm{UCC}$ 는 기존의 전통적인 커뮤니케이션 미디어 와 다르게, 사용자 경험을 축적하여 보다 민감한 정보를 제공하는 '풍부성(richness)'과 RSS(rich summary site) 혹 은 트랙백과 같은 기능을 이용하여 누구든지 관심 있는 자에게 정보를 배급할 수 있는 '도달(reach)'을 동시에 만
족시킬 수 있다[16, 21]. 이에 따라 인터넷 이용자들이 블 로그(e.g. 이를루스, 네이버 블로그), 단문 블로그(e.g. 미 투데이, 트위터), 지식-In, 전문 동영상 $\mathrm{UCC}$ 사이트 및 포 털에 유무선 인터넷 매체를 이용하여 콘텐츠를 생산하고 유통하는 것이 급격히 증가하고 있다. 이러한 폭발적인 $\mathrm{UCC}$ 의 증가로 인해 콘텐츠의 다양성과 양적인 측면의 발전은 거듭하고 있지만, 반대로 UCC 질적 수준은 여러 가지 측면에서 문제점 또는 이슈를 제기하고 있다. 즉, 비 전문가인 인터넷 이용자들이 제작해서 올리는 콘텐츠에 대한 품질관리가 제대로 되지 않고 있어 이들 콘텐츠에 대한 신뢰문제가 대두되고 있다. UCC는 과거 소수 전문 가 집단이 자체 기준을 갖고 정보 오류를 걸러내 공개하 는 구조에 비해 설익은 정보와 잘못된 정보가 유통될 개 연성이 있다[3]. 나아가 RSS와 트랙백과 같은 실시간 콘 텐츠 유통기술에 의해 순식간에 인터넷 이용자들 간에 잘못된 콘텐츠 및 정보가 공유될 수 있기 때문에 $\mathrm{UCC}$ 에 서 정보의 이슈가 더욱 중요한 문제가 될 수 있다. 정확 하지 않은 정보들이 확산되고, 사회적인 문제를 발생시키 게 되는데, 이러한 현상들이 반복되면 UCC나 인터넷 활 용과 관련된 전반적인 서비스들이 불신을 받게 될 것이 고 이로 인해 전반적인 서비스 이용도는 낮아 질 것이기 때문이다[1].

이에 본 연구에서는 $\mathrm{UCC}$ 의 서비스 품질 중에서 특히 정보품질을 측정하기에 적합한 모델을 개발하기 위해 먼 저 a) 문헌 연구를 통해 선행연구에서 다루어졌던 웹 사 이트 평가 모델과 Web 1.0 의 온라인 쇼핑몰(B2C) 기반 e-SQ 모델의 요소들을 검토하였다. 다음 이러한 기존 e-SQ 모델을 UCC e-SQ 모델에 적용함에 있어 지적되는 한계점을 정보 품질영역에서 도출하였다. 하지만 한계점 을 극복하기 위해 필요한 UCC e-SQ 요소는 기존 선행연 구의 부족으로 문헌연구만으로 도출될 수 없기 때문에 본 연구에서는 $b$ ) Focus Group Interview(FGI)와 전문가 인터뷰를 통한 질적 연구 방법론에 기초해서 정보 품질 면에서의 UCC e-SQ 요소, 하위 요소와 세부 측정항목을 도출하였다. 그리고 도출된 항목은 다시 역으로 Web 2.0 관련 선행연구에서 실제 그 중요성이 논의되고 있는지 다시 한번 광범위한 문헌 연구를 통해 검토되었다. $c$ ) 확 정된 설문 문항의 타당성과 신뢰성을 검증하기 위해 본 연구에서는 한국과 미국 대학생 집단을 대상으로 총 221 부의 설문지를 수집하여 구조 방정식 모형을 이용하여 본 연구가 제안한 UCC e-SQ 측정모델을 검증하였다. 아 직까지 $\mathrm{Web} 2.0$, 보다 구체적으로 $\mathrm{UCC}$ 의 개방성, 참여 성, 공유성 등을 반영한 e-SQ 모델이 부재한 현실에서 광 범위한 계량적, 질적 연구방법을 토대로 도출된 본 연구 의 $\mathrm{UCC}$ e-SQ의 정보품질평가 모델은 향후 기업과 $\mathrm{UCC}$ 
서비스 기업이 UCC란 새로운 트랜드를 어떻게 운영해야 하는지, 그리고 나아가 이러한 새로운 집단지성을 어떻게 하나의 비즈니스 모델로 발전시킬 수 있을 것인지에 대 한 가능성을 시사함에 있어 중요한 역할을 할 것으로 기 대된다.

\section{2. e-SERVQUAL에 관한 기존 연구}

Web 1.0 시대의 $\mathrm{B} 2 \mathrm{C}$ 기업은 인터넷을 서비스와 상품 을 판매하는 중요한 채널로 유지하면서, 온라인 고객의 재구매나 충성도를 높여 기업의 수익을 향상시키기 위한 목적으로 인터넷 상에서 고객에 전달되는 주요 서비스 요소들을 탐색하였다. 이러한 서비스 요소들을 탐색하여 모델화한 e-service quality(e-SQ)란 온라인 상에서 고객과 기업과의 상호작용과 경험의 품질을 반영한 개념으로, Zeithaml et al. (2002)은 "웹사이트가 고객으로 하여금 제 품이나 서비스를 효과적, 효율적으로 쇼핑, 구매, 배달을 할 수 있도록 지원해주는 정도"로 정의하고 있다[37]. 본 장에서는 Web 2.0 시대의 $\mathrm{UCC}$ 웹사이트에 적합한 e-SQ 모델을 개발하는 과정에서 기초가 되는 Web 1.0 시대의 e-SQ 모델에 대한 기존 연구를 검토하여 그 한계점과 Web 2.0 의 e-SQ로의 적용 가능성을 모색하고자 한다.

e-SQ 모델의 초기 연구는 사이트 개발자의 입장에서 고객의 기대치를 예상하는 웹사이트 평가 모델에 기초하 였다. 주로 웹사이트의 기술적 능력을 위주로 정보, 서비 스는 기업의 전반적 차원에서 평가해왔던 초기 모델에 대하여, Parasuraman et al.(2005)[30]을 중심으로 사용자 의 경험치에 근거하여 서비스 품질에 주목하는 2 세대 연 구로 이어진다. 그러나 Web2.0 사이트의 등장은 사용자 가 소비자의 입장에서 참여자의 입장으로 전환되는 특성 으로 말미암아, 사용자 경험치의 관점 변화를 토대로 한 새로운 요소의 등장과 기존 요소의 수정을 포함하고 있다.

본격적인 e-SQ 연구는 서비스 제공자로서의 웹사이트 가 고객의 경험치를 고려한 서비스에 보다 더 주목해야 한다는 관점에서 시작되었다. 초기의 웹사이트 평가모델 이 정보 혹은 서비스적 요소보다 고객 서비스를 위한 제 품 혹은 시스템 측면을 강조하여 이루어졌던 데에서 나 아가, 온라인 쇼핑몰 등의 전자상거래에서 사용자가 직접 경험하는 서비스적 측면을 부각하여 웹 사이트 품질을 평가하려는 연구들이다 $[8,9,23,30,34,37]$. 인터넷 쇼 핑몰 대상의 전자상거래 중심 e-SQ 연구는 거래 위주 연 구에서 시작하여 나아가 통합적 서비스 품질에 대한 평 가까지 포함한다. 또한 DeLone and McLean(2003)[13]은 이전의 정보시스템 성공요인 연구(1992)[12]에서 종합하
였던 연구 내용을 이후 업데이트하여, 전자상거래사이트 의 성공을 설명할 수 있는 정보의 개인화 정도, 완전성, 적절성, 이해용이성 및 보안성 등을 추가하여 제시하고 있다.

상거래 평가를 위한 연구로서의 WebQual 모델은 기존 마케팅 분야에서 서비스 품질 측정도구로 활용되어 오던 모델을 전자상거래 사이트 평가에 적용함으로써 고객의 지각에 근거한 사이트 품질 지수를 제시한다 $[9,34,35]$. 그러나 이 연구들의 관심은 구매 프로세스 혹은 고객 만 족도 등에 국한되었고 거래의 직접 참여자 대상이 아니 었으므로, 사용자 서비스 측면을 제외시킴으로써 전반적 인 서비스 품질 평가가 이루어지지 못하였다. Zeithaml et al.(2000)[38]의 연구 이후 Parasuraman et al.(2005)[30]에 이르러 비로소 사용자 경험에 입각한 서비스 품질 요인 을 포함하여 전반적인 온라인 서비스 품질 모델이 제시 된다. Parasuraman et al.(2005)[30]은 수많은 실증연구를 통하여 전자상거래 사이트 상에서의 서비스 품질을 측정 하는 총체적인 서비스 품질 모델을 개발하였다.

$\mathrm{Web} 1.0 \mathrm{~B} 2 \mathrm{C}$ 환경에서 개발된 $\mathrm{e}-\mathrm{SQ}$ 은 정보사용자 (online customer)에 대한 정보제공자 (online provider)의 관점에서 사용되었던 평가기준으로 이해할 수 있다. 그러 나 정보제공자와 정보사용자의 구분이 없어지고 있는 Web 2.0 환경의 UCC 사이트, 즉 재화를 거래하는 상업 적 사이트뿐 아니라 자신의 정보, 지식 등을 표현하고 교 환하는 UCC 사이트에 있어서의 서비스 품질을 반영하기 에 기존 Web 1.0 e-SQ은 한계가 있다. 따라서 기존 e-SQ 모델의 한계점을 정보품질 측면에서 고려해보고자 한다.

즉, 웹 사이트 평가모델과 2세대 e-SQ 모델 모두는 "정 보" 품질에 대해서 시스템 혹은 서비스와 연계하여 고려 함으로써 세분화시켜 분석하지 못하고 있다. 그러나 Ariely (2000)가 지적하였듯 사용자는 Web2.0 즉 UCC 시 대는 더 많은 정보를 통제할 수 있기 때문에 정보를 통합 하고 기억 하는 등 정보 활용능력이 개선되는 환경이다 [7]. 웹 2.0 환경에서 유통되는 정보는 정보제공자와 정보 사용자의 구분이 없어지는 특성 상 정보 품질 그 자체에 대한 평가가 더욱 요구된다고 판단된다. 때문에 정보의 가용성과 깊이는 더욱 중요한 요소가 된다. Web1.0과 차 별화되는 $\mathrm{UCC}$ 의 주요 키워드 특성을 자발적인 사용자의 컨텐츠 창조, 공유 및 개방으로 보면서, 그들 특성의 중심 에 위치한 정보 품질의 요소는 세분화시켜 분석할 가치 가 있다. 따라서 본 연구는 정보시스템평가요인과 e-SQ 에 대한 평가요인을 종합적으로 분석[12, 13]하여 UCC 서비스 사이트의 정보품질요인을 새롭게 개념화하고자 한다. 기존의 전통적인 커뮤니케이션 미디어와 다르게, $\mathrm{Web} 2.0$ 사이트에서는 사용자 경험을 축적하여보다 민감 
하고 풍부한 정보가 소통될 수 있으며, RSS 혹은 트랙백 과 같은 기능을 이용하여 누구든지 관심 있는 사용자에 게 도달될 수 있다 $[16,21]$. 개방, 참여, 협업 등의 활동이 주가 됨으로써, 예를 들어 기존의 인터넷 활동목적 중 하 나인 정보취득이라는 동일한 목적이라 할지라도 이는 일 방향 소통 즉 누군가가 업로드해 놓은 정보를 일방적으 로 다운 받는 식이 아니라 그에 대한 나의 의견을 내놓을 수 있음으로 말미암아 견제 가능한 정보를 제공받을 수 있다[11]. 또한 사용자 경험을 축적하여 누구나 정보 제 공자가 될 수 있도록 지원하는 새로운 기술적 요인으로 인하여 사용자 상호 간의 검증, 출처의 제시 등의 상호 믿을 수 있는 정보 소통이 중요하다. 이와 같이 새롭게 추가적으로 평가되어야 할 정보 품질요인들을 전문가 인 터뷰를 통해 도출할 것이다. 즉, 새롭게 등장한 Web2.0환 경은 $\mathrm{UCC}$ 를 통해 보다 적절하게 고려해야 하는 서비스 품질 제고의 필요성을 부른다. 사용자가 궁극적인 생산 자, 창조자가 될 수 있는 $\mathrm{UCC}$ 서비스 품질요소를 전문가 와의 인터뷰를 통하여 도출하도록 한다.

\section{Focus Group 및 전문가 인터뷰}

본 연구는 기존의 Web 1.0 기반의 e-SQ 평가를 위한 변 수로는 최근의 UCC 서비스 품질을 제대로 평가할 수 없 을 것으로 판단하여 최근의 $\mathrm{Web} 2.0$ 의 $\mathrm{UCC}$ 서비스 품질 을 평가하기 위한 FGI를 수행하였다. FGI란 소수의 응답 자와 비구조화 되고(unstructured) 자연스러운 방식으로 잘 훈련된조정자에 의해서 수행되는 면접기법으로, 집중 적인 대화를 통하여 정보를 찾아내게 된다[26]. 본 연구 에서는 대학에서 직접 $\mathrm{UCC}$ 를 창작하여 각종 $\mathrm{UCC}$ 사이 트에 올리는 등의 활동을 하고 있는 UCC 동아리 학생들 15 명, 3 개 그룹을 대상으로 FGI를 수행하였다. FGI 수행 결과, Web 1.0 을 근간으로 한 기존의 문헌연구로부터 도 출된 평가항목 외에 새로운 항목들이 추출되었다. 구체적 으로 살펴보면 다음과 같다.

즉, 정보성(정보풍부성, 정보유용성), 신뢰성(정보신뢰 성, 정보피드백), 흥미성(정보흥미성, 정보기발성) 등의 크게 3 개의 범주들이 제시되었다. 먼저, 정보성 범주에서 정보풍부성은 다양한 주제로 충분한 정보를 얻을 수 있 어야 한다고 참여자들은 지적하고 있다. 두 번째, 정보유 용성 측면에서는 UCC 사이트에서 제공하는 정보나 자료 는 검증된 정보이어야 하며, 정보의 출처가 제시되고, 정 확해야 한다고 지적하였다. 신뢰성 범주에서는 UCC 사 이트는 검색 시 허위 정보를 배제하기 위한 필터링 기술 의 필요성 등의 정보신뢰성과 광고나 각종 유해물을 걸
러내 안정된 정보환경을 유지해야 한다는 정보피드백 등 의 개념이 제시되었다. 마지막으로 흥미성 범주에서는 정 보흥미성과 정보기발성의 개념이 제시되었는데, 이는 $\mathrm{UCC}$ 사이트는 다양한 자료와 호기심을 유발할 수 있는 아이템의 제공과 여기서 제공한 정보를 통해 흥미를 느 껴야 함을 지적한다.

이렇게 도출된 범주와 개념들을 바탕으로 문헌연구에 서 찾아낸 평가요인들과 항목들을 보완하여 평가설문지 를 완성하였다. 이를 다시 한국의 대표적인 UCC 서비스 전문가 3 명으로부터 검토 받아 수정 보완하여 최종적으 로 평가항목을 작성하였다. 구체적으로 살펴보면 아래 표 1 과 같다.

[표 1] 도출된 UCC 서비스 사이트 품질 변수

\begin{tabular}{|c|c|c|}
\hline 1차 factor & 2차 factor & 세부 항목 \\
\hline \multirow[b]{2}{*}{ 정보성 } & 정보풍부성 & $\begin{array}{l}\text { 주제 다양성 } \\
\text { 정보 충분성 }\end{array}$ \\
\hline & 정보유용성 & $\begin{array}{l}\text { 정보의 활용성 } \\
\text { 목적적합성 } \\
\text { 정확성 } \\
\text { 최신성 }\end{array}$ \\
\hline \multirow{2}{*}{ 신뢰성 } & 정보신뢰성 & 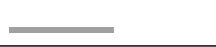 \\
\hline & 정보피드백 & 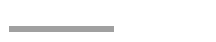 \\
\hline \multirow{2}{*}{ 흥미성 } & 정보흥미성 & 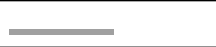 \\
\hline & 정보기발성 & 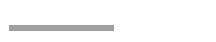 \\
\hline
\end{tabular}

\section{4. 연구 방법}

\section{1 자료의 수집}

본 연구에서는 UCC서비스를 이용하는 대학생을 대상 으로 한국과 미국에서 2009년3월부터 4월까지 약 2달간 설문조사를 수행하였다. 설문의 주요 주제로 다루어지는 $\mathrm{UCC}$ 는 주로 젊은 인터넷 사용자 층을 중심으로 공유와 창작이 이루어지고 있다는 점에서 대학생을 대상으로 삼 았다. 설문대상으로 선정된 개인들에게 설문지를 보내기 이전에 이들 각각에게 본 연구의 취지를 설명하였고 설 문에 응답해 줄 것을 요청하였다. 이들 가운데서 설문에 응답해 줄 것을 약속한 설문 대상자들을 만나거나 E-mail 발송 등의 방법을 통해 한국과 미국에서 각각 총 150 부 의 설문지를 발송하였다. 본 연구의 궁극적 목적은 UCC 의 e-SQ 모델 개발이기 때문에 일반화된 모델 개발을 위 해서는 보다 다각적이고 다문화적 차이가 반영되어야 한 다는 판단 하에 한국과 미국, 동서양의 샘플을 둘 다 채 
택하기로 하였다. 한국에서는 서울, 천안, 부산 등 4 개 대 학의 대학생들에게 설문지를 배포하였으며, 미국에서는 Florida주의 Florida State University의 대학생들에게 설문 지를 배포하였다. 설문지를 발송한 1 주 이상 경과하였으 나 설문응답이 없는 경우에는 직접 면접하거나 전화 및 메일을 통해 신속한 설문협조를 부탁하였다. 이러한 과정 을 통하여 한국에서는 총 119 개의 설문지가 회수되었으 며, 미국에서는 132 개의 설문지가회수되었다. 이 가운데 불성실하게 응답한 설문으로 분류된 설문지가한국의 경 우 18 개, 미국은 각각 11 개씩이었으므로 최종 분석에는 한국 설문지 101 개와 미국 설문지 121 개, 총 221 개의 설 문지가 사용되었다.

\section{2 측정항목 개발}

본 연구에서 다루는 각 변수들은 Web 2.0 가운데 UCC 의 service quality의 정보품질을 측정할 수 있는 항목에 대한 개념적 정의를 담고 있다. 정보품질의 상위 1 차 요 인을 중심으로 각 상위 요인에 속하는 2차 요인이 질적 연구 및 선행 연구를 바탕으로 설문지 항목으로 개발되 었다. 즉, 정보품질은 3 가지 1 차 요인 (정보성, 신뢰성, 흥 미성) $\rightarrow 6$ 가지 2차 요인 (정보-풍부성, 유용성, 신뢰성, 피드백, 흥미성, 기발성)을 중심으로 39 개 설문 항목이 개발되었다. 각 설문항목은 질적 연구 결과 및 $\mathrm{Web} 1.0$ 및 $\mathrm{Web} 2.0$ 에서의 정보의 중요성을 주장하는 기존 문헌 의 개념을 채택, 이를 $\mathrm{UCC}$ 에 맞게 변형하여 설문항목으 로 개발하였다.

[표 2] 정보 품질의 측정

\begin{tabular}{|c|c|c|}
\hline \multicolumn{2}{|c|}{ 정보품질 요인 } & 관련 연구 \\
\hline 정보성 & $\begin{array}{l}\text { 정보 풍부성 } \\
\text { 정보 유용성 }\end{array}$ & {$[8,11,13,16,21]$} \\
\hline 신뢰성 & $\begin{array}{l}\text { 정보 신뢰성 } \\
\text { 정보 피드백 }\end{array}$ & [13] \\
\hline 흥미성 & $\begin{array}{l}\text { 정보 흥미성 } \\
\text { 정보 기발성 }\end{array}$ & [5] \\
\hline
\end{tabular}

\section{5. 연구 결과}

\section{1 척도정화(Scale Reduction)}

본 연구에서는 UCC 사이트 정보 품질요인에 대한 측 정항목들을 IS 및 웹 서비스 품질 평가에 대한 연구와 $\mathrm{UCC}$ 참여자/전문가와의 심층적인 인터뷰를 통해 도출
하였다. 다문항을 이용한 UCC 사이트 품질차원들에 대 한 신뢰성 검정을 위해 먼저, 측정문항과 그 문항을 제외 한 여타 문항들 사이의 상관관계를 분석하였다. 수정문항 대 전체문항간의 상관관계가 0.4 이상이면 특정개념을 측정하는 문항들로 이루어진 모집단에서 추출한 것으로 파악할 수 있다[2]. 그런데, 주제다양성(I1, I2, I3), 최신성 (I15) 및 정보피드백(I9)의 상관계수가 0.4보다 작게 나타 나서, 정보품질 측정항목에서 제외되었다.

[표 3] 개별문항 대 전체 문항 간 상관관계 분석

\begin{tabular}{|c|c|c|}
\hline $\begin{array}{l}\text { 정보 품질 } \\
\text { 요인 }\end{array}$ & 측정항목 & $\begin{array}{c}\text { 수정문항 대 } \\
\text { 전체문항간의 } \\
\text { 상관관계 }\end{array}$ \\
\hline \multirow{4}{*}{$\begin{array}{l}\text { 정보 } \\
\text { 충분성 }\end{array}$} & I4 & .543 \\
\hline & I5 & .628 \\
\hline & I6 & .515 \\
\hline & I7 & .618 \\
\hline \multirow{3}{*}{$\begin{array}{l}\text { 정보 } \\
\text { 피드백 }\end{array}$} & I8 & .650 \\
\hline & I10 & .689 \\
\hline & I11 & .738 \\
\hline \multirow{3}{*}{ 최신성 } & I12 & .761 \\
\hline & II3 & .792 \\
\hline & I14 & .714 \\
\hline \multirow{3}{*}{$\begin{array}{l}\text { 정보 } \\
\text { 활용성 }\end{array}$} & I16 & .488 \\
\hline & I17 & .754 \\
\hline & I18 & .712 \\
\hline \multirow{4}{*}{$\begin{array}{l}\text { 목적 } \\
\text { 적합성 }\end{array}$} & I19 & .685 \\
\hline & $\mathrm{I} 20$ & .713 \\
\hline & $\mathrm{I} 21$ & .643 \\
\hline & I22 & .644 \\
\hline \multirow{4}{*}{ 정확성 } & I 23 & .487 \\
\hline & I24 & .550 \\
\hline & I25 & .620 \\
\hline & I26 & .518 \\
\hline \multirow{4}{*}{$\begin{array}{l}\text { 정보 } \\
\text { 신뢰성 }\end{array}$} & I27 & .599 \\
\hline & I28 & .693 \\
\hline & I29 & .729 \\
\hline & I30 & .671 \\
\hline \multirow{5}{*}{$\begin{array}{l}\text { 정보 } \\
\text { 흥미성 }\end{array}$} & $\mathrm{I} 31$ & .715 \\
\hline & $\mathrm{I} 32$ & .723 \\
\hline & $\mathrm{I} 33$ & .638 \\
\hline & I34 & .754 \\
\hline & I35 & .541 \\
\hline \multirow{4}{*}{$\begin{array}{l}\text { 정보 } \\
\text { 기발성 }\end{array}$} & $\mathrm{I} 36$ & .630 \\
\hline & I37 & .655 \\
\hline & I38 & .621 \\
\hline & I39 & .458 \\
\hline
\end{tabular}


$\mathrm{UCC}$ 서비스 사이트의 정보품질 평가 모델 개발

\section{2 신뢰성과 타당성 검증}

본 연구에서 사용된 척도는 기존의 연구에서 이미 실 증적으로 검증된 문항과 $\mathrm{UCC}$ 이용자 및 전문가에 대한 심층 인터뷰를 통해 새롭게 개발한 문항을 모두 사용하 였다. 따라서 다차원의 구성개념을 측정하는 문항들을 모 두 투입하여 탐색적으로 요인들을 추출하는 방식으로 요 인구조를 파악하였다. 요인추출 방식은 주성분분석을 이 용하였고, 요인 부하량은 0.5 이상을 기준으로 하였다 [19]. 그리고 추출되는 요인 수는 일반적 기준인 고유값 이 1 이상인 요인만을 추출하도록 하였다. 추출된 최종 차 원들에 대해 Cronbach' a 계수값에 의한 문항 내적 일관 성 검정을 실시한 결과 모든 요인들이 Cronbach' a 계수 값 기준치인 0.7 을 초과하는 것으로 나타났다. 그러나 새 로 개발된 문항이나 그 문항을 포함하는 경우에는 0.6 을 최저치로 허용할 수 있다[28]. 표 4는 정보 품질 측정항목 들에 대한 신뢰도 분석과 타당성 분석 결과를 제시하고 있다. 신뢰도 분석에서는 123 과 139 이 제거되었다. 또한 정보활용성과 목적적합성이 하나의 요인으로 합쳐졌으 며, 역시 정보흥미성과 정보기발성이 하나의 요인으로 합 쳐졌다.

나아가 본 연구에서는 앞서 실시한 탐색적 요인 분석 을 통해 추출된 시스템 품질에 대한 최종 문항들을 가지 고 확인적 요인 분석을 실시하였다. 확인적 요인 분석은 탐색적 요인 분석과 달리 측정변수가 잠재변수에 대한 통계적 검정이 가능하고 측정모형에 대한 보수적인 검증 방법이라고 할 수 있다. 측정모형에 관한 통계적 적합도 를 검증하기 위하여 절대적합지수의 판단기준으로 $\mathrm{x}^{2}$ 값 (카이자승 값은 작을수록 바람직, $\mathrm{p}>0.05$ 이면 바람직) GFI(Goodness-of-Fit Index: 0.90 이상), RMSEA(Root Mean Square Error of Approximation: 0.05 미만이면 매 우 잘 적합, 0.05-0.1이면 잘 적합), 증분적합도지수로는 TLI (Turker-Lewis Index: 0.9이상), CFI (Comparative Fit Inedex) 간명적합도지수로는 PGFI (Parsimonious Goodness of Fit Index: 0.5이상) 등을 이용하였다. 정보 품질모형의 적합도 지수를 살펴보면, RMSEA가 0.058로 $\mathrm{Hu} \&$ Bentler(1999)[20]가 제시한 0.6 기준치 보다 낮게 나타났으며, $\operatorname{TLI}(0.909), \operatorname{CFI}(0.921)$ 는 기준치인 0.9 보다 높게 나타났으나 GFI(0.843)는 다소 낮게 나타났다. 또한 $\operatorname{PGFI}(0.688)$ 도 기준치인 0.5 보다 높게 나타나 측정모형 의 적합도가 어느 정도 좋은 것으로 나타났다.
[표 4] 신뢰도 및 타당도 분석 결과

\begin{tabular}{|c|c|c|c|c|c|}
\hline \multirow{2}{*}{ 요인 } & \multirow{2}{*}{$\begin{array}{l}\text { 측정 } \\
\text { 항목 }\end{array}$} & \multirow{2}{*}{$\begin{array}{l}\mathrm{EFA}^{\mathrm{a}} \\
\text { 요인 } \\
\text { 부하량 }\end{array}$} & \multicolumn{2}{|c|}{ CFA } & \multirow{2}{*}{$\begin{array}{c}\text { Cronbach } \\
\text { alpha }\end{array}$} \\
\hline & & & 표준화계수 & t-value & \\
\hline \multirow{3}{*}{$\begin{array}{l}\text { 정보 } \\
\text { 충분성 }\end{array}$} & I5 & .518 & .667 & 10.242 & \multirow[t]{3}{*}{$(0.735)$} \\
\hline & I6 & .817 & .636 & 13.267 & \\
\hline & I7 & .694 & .777 & - & \\
\hline \multirow{3}{*}{$\begin{array}{c}\text { 정보 } \\
\text { 피드백 }\end{array}$} & I8 & .720 & .890 & 13.536 & \multirow[t]{3}{*}{$(0.832)$} \\
\hline & I10 & .824 & .831 & - & \\
\hline & I11 & .815 & .790 & 14.477 & \\
\hline \multirow{4}{*}{ 최신성 } & $\mathrm{I} 12$ & .715 & .847 & 19.002 & \multirow[t]{4}{*}{$(0.863)$} \\
\hline & II3 & .757 & .890 & - & \\
\hline & I14 & .694 & .769 & 16.452 & \\
\hline & I4 & .553 & .888 & 12.912 & \\
\hline \multirow{7}{*}{$\begin{array}{c}\text { 정보 } \\
\text { 활용성 }\end{array}$} & $\mathrm{I} 16$ & .534 & .709 & 11.789 & \multirow[t]{7}{*}{$(0.885)$} \\
\hline & I17 & .772 & .651 & 10.848 & \\
\hline & I18 & .798 & .643 & 10.242 & \\
\hline & I19 & .704 & .803 & 13.267 & \\
\hline & $\mathrm{I} 20$ & .726 & .786 & 13.085 & \\
\hline & $\mathrm{I} 21$ & .754 & .711 & 11.817 & \\
\hline & $\mathrm{I} 22$ & .544 & .709 & - & \\
\hline \multirow{3}{*}{ 정확성 } & $\mathrm{I} 24$ & .736 & .599 & 9.689 & \multirow[t]{3}{*}{$(0.721)$} \\
\hline & $\mathrm{I} 25$ & .619 & .820 & - & \\
\hline & I26 & .635 & .614 & 9.939 & \\
\hline \multirow{4}{*}{$\begin{array}{c}\text { 정보 } \\
\text { 신뢰성 }\end{array}$} & $\mathrm{I} 27$ & .681 & .543 & 10.057 & \multirow[t]{4}{*}{$(0.838)$} \\
\hline & $\mathrm{I} 28$ & .838 & .637 & 12.169 & \\
\hline & I29 & .717 & .872 & - & \\
\hline & $\mathrm{I} 30$ & .683 & .862 & 17.912 & \\
\hline \multirow{8}{*}{$\begin{array}{c}\text { 정보 } \\
\text { 흥미성 }\end{array}$} & I31 & .698 & .753 & 14.006 & \multirow[t]{8}{*}{$(0.907)$} \\
\hline & I32 & .728 & .795 & 14.903 & \\
\hline & I33 & .717 & .711 & 13.190 & \\
\hline & I34 & .757 & .819 & 15.615 & \\
\hline & $\mathrm{I} 35$ & .625 & .659 & 12.002 & \\
\hline & I36 & .775 & .772 & - & \\
\hline & I37 & .743 & .719 & 13.348 & \\
\hline & I38 & .713 & .728 & 13.560 & \\
\hline
\end{tabular}

Note: ${ }^{a}$ Extraction Method: Principal Component Analysis. Rotation Method: Varimax with Kaiser Normalization.

Hypothesized model with standardized parameter estimates for the full sample $(N=221){ }^{2}=893.462, d f=431 \quad(\mathrm{p}<.001)$; $\mathrm{GFI}=0.843 ; \mathrm{TLI}=0.909 ; \mathrm{CFI}=0.921 ; \mathrm{PGFI}=0.688 ; \mathrm{RMESA}=0.058$.

\section{6. 결론 및 시사점}

본 연구가 제시하는 UCC SQ 평가모델에 있어서 Web2.0기반의 e-SQ 평가를 위한 변수는 참여자로서의 사용자의 활동 평가요인이 주를 이루고 있다. 즉 정보 품 질 측면에서 사용자의 참여, 개방 및 공유의 특성을 반영 할 수 있는 측정요인들이 검증되었다.

정보 품질 측면에서 정보 활용능력의 개선이 더 많이 반영된 평가 요인들을 검증하였다. 정보 활용능력의 개선 
은 사용자와 사이트 업체 및 사용자와 사용자 간 더 많은 정보를 통제할 수 있기 때문에 요구되는 현상으로, 예를 들어 위키피디아와 같은 사이트는 사용자 간의 정보 통 제를 원활히 허용함으로써 Web1.0보다 진보된 Web2.0 기반 정보 품질을 제공한다. 이와 같은 정보 품질을 평가 요인으로 ‘정보풍부성'과 ‘정보유용성'과 같은 기존 평가 요인에 더하여 '정보신뢰성'과 '정보안정성'을 제시한다. 정보신뢰성과 정보안정성은 Web2.0 기반 사이트가 모든 사용자가 참여자로서 더 많은 정보를 유통시킬 수 있는 $\mathrm{Web} 2.0$ 환경 상 평가해야 할 필수불가결한 요인이다. 또 한 ‘정보흥미성’과 ‘정보기발성’은 Web2.0 현상 중 하나 인 관심의 경제학 즉, 정보의 공급자보다 수요자가 더 적 다는 속성으로 말미암아 정보 자체가 사용자의 관심을 이끌 수 있는 속성을 지녀야 할 필요성을 반영하고 있다.

본 연구가 시사하는 바는 다음과 같다.

첫째, 참여자로서의 사용자로 특징지어지는 Web2.0 기 반 사이트에 대해 총체적인 e-SQ모델을 개발한 첫 시도 이다. 본 연구가 제시하는 $\mathrm{UCC} \mathrm{SQ}$ 평가 모델은 기존 Web1.0 기반의 e-SQ 모델이 설명하지 못하고 있는 사용 자와 사용자 간의 문제 및 사용자 경험치 관점을 반영한 다. 둘째, 기존의 e-SQ 문헌연구 및 전문가집단의 심층면 접을 통한 연구방법론을 활용함으로써, Web2.0 기반의 새로운 영역 평가에 대해 다양하고 완결성 있는 연구 근 거를 제시하고 있다. 셋째, 자료수집에 있어서 한국 및 미 국의 자료를 동시에 수집, 분석하여 일관성 있는 결과를 도출함으로써, 국경 없는 웹의 범용성을 반영하고 있다.

\section{참고문헌}

[1] 이한희, 강소라, 김유정,"UCC 서비스 사이트의 신뢰가 $\mathrm{UCC}$ 사용자에 미치는 영향," 한국콘텐츠학회 논문지, 제9권, 제12호, pp.759 776, 2009.

[2] 이형석, 사회과학논문의 기초, 한경사, 2008.

[3] 전자신문, http//www.etnews.co.kr, 2009.

[4] Ahmad, S., "Service Failures and Customer Defection: A Closer Look at Online Shopping Experiences,"Managing Service Quality, Vol.12, No.1, pp.19-29, 2002.

[5] Amit, R., and Zott, C.,"Value Creation in E-Business," Strategic Management Journal, Vol.22, pp.493-520, 2001.

[6] Anderson, P., "What is Web 2.0? Ideas, Technologies and Implications for Education," Joint Information Systems Committee, Retrieved from http://www.jisc.ac.uk/media/documents/techwatch/ tsw0701b. pdf, 2007.

[7] Ariely, D., "Controlling the Information Flow: Effects on Consumers' Decision Making and Preferences," Journal of Consumer Research, Vol.27, No.2, pp.233-248, 2000.

[8] Bansal, H., McDougall,G.., Dikolli, S., and Sedatole, K. "Relating E-satisfaction to Behavioral Outcomes: An Empirical Study," The Journal of Services Marketing, Vol.18, No.4/5, pp.290-302, 2004.

[9] Barnes, S., and Vidgen, R., "An integrative approach to the assessment of e-commerce quality,"Journal of Electronic Commerce Research, Vol.3, No.3, pp.114-127, 2002.

[10] Bauer, C. and Scharl, A. "Acquisition and Symbolic Visualization of Aggregated Customer Information for Analyzing Web Information Systems", Proceedings of the 32nd Hawaii International Conference on System Sciences (HICSS-99). Vol.V, 1999.

[11] Dearstyne, B. W.,"Oh, My!,"Information Management Journal, Vol.41, No.4, pp.25-33, 2007.

[12] DeLone, W., and McLean, E. "Information Systems Success: The Quest for the Dependent Variable," Information Systems Research, Vol.3, No.1, pp.60-95, 1992.

[13] DeLone, W., and McLean, E. "The DeLone and McLean Model of Information Systems Success: A Ten-Year Update," Journal of Management Information Systems, Vol.19, No.4, pp.9-30, 2003.

[14] Devaraj, S., Fan, M., and Kohli, R. "Examination of Online Channel Preference: Using the Structure-Conduct-outcome Framework," Decision Support Systems, Vol.42, No.2, pp.1089-1103, 2006.

[15] Dutta, S., and Segev, A. "Business Transformation on the Internet," European Management Journal, Vol.17, No.5, pp.466-476, 1999.

[16] Evans P., and Wurster, T. Blown to Bits: How the New Economics of Information Transforms Strategy, Boston M.A.: Harvard Busienss School Press, 2000.

[17] Floh, A. and Treiblmaier H. " What Keeps the E-Banking Customer Loyal? A Multigroup Analysis of the Moderating Role of Consumer Characteristics on E-Loyalty in the Financial Service Industry", Journal of Electronic Commerce Research, Vol.7, No.2, pp. 97-110, 2006.

[18] Gaudin, S., Companies Failing at Online Customer Service. Retrieved from http://itmanagement.earthWeb.com/erp/article.php/ 1588171, 2003.

[19] Hair, J.F., Black, W.C., Babin, B.J., Anderson, R.E. and Tatham, R.L. Multivariate Data Analysis (6th Edition), 
Pearson, 2006.

[20] Hu, L., and Bentler, P. M. "Cutoff Friteria for Fit Indexes in CovarianceStructure Analysis: Conventional Criteria versus New Alternatives," Structural Equation Modeling, Vol.6, pp.1-55, 1999.

[21] Lazar, I.. "Creating Enterprise2.0 from Web2.0," Business Communications Review, Vol.37, No.8, pp.14-16, 2007.

[22] Lennon, R. and J. Harris, "Customer Service on the Web: A Cross-Industry Investigation," Journal of Targeting, Measurement and Analysis for Marketing, Vol.10, No.4, pp.325-38,2002.

[23] Liu, C. and Arnett, K.P. Exploring the factors associated with Web site success in the context of electronic commerce, Information \& Management, Vol. 38, pp. $23-33,2000$.

[24] LoCascio, R., A Web Site Is Not a Vending Machine. Retrieved from http://www.clickz.com/crm/onl_cust_ serv/article.php/825521, 2000.

[25] Loiacono, E., Watson, R. T., and Goodhue, D. "WebQualTM: A Web Site Quality Instrument," American Marketing Association's Winter Marketing Conference, Austin, TX, 2002.

[26] Malhotra, N. Marketing Research: An Applied Orientation $\left(3^{\text {rd }}\right.$ ed.). Publisher: Pearson Education, 2006.

[27] Nielsen, J.. Designing for usability. Indiana: New Riders Publications, 2000.

[28] Nunnally, J. Psychometric Theory ( $2^{\text {nd }}$ ed.), New York: McGraw-Hill, 1978.

[29] Palmer, J.W., "Web site usability, design, and performance metrics", Information Systems Research, Vol. 13, No.2, pp.151-67, 2002.

[30] Parasuraman, A., Zeithaml, V., and Malhotra, A. "A Multiple-Item Scale for Assessing Electronic Service Quality," Journal of Service Research, Vol.7, No.3, pp.213-233, 2005.

[31] Pastore, M. Online Customer Service Still Has Work to Do. Retrieved from

http://cyberatlas.internet.com/markets/retailing/article/ 0,6061_577051,00.html, 2001.

[32] Sprengers, J. "Objective Evaluation of Likely Usability Hazards - Preliminaries for User Testing," Rtrieved from http://www.abeleto.nl/resources/articles/objective1.html, 2004.

[33] Szymanski, D.M., and Hise, R.T. "E-satisfaction: An Initial Examination," Journal of Retailing, Vol.76, No.3, pp.309-322, 2000.

[34] Wolfinbarger, M., and Gilly, M. "E-Tail:
Dimensionalizing, Measuring and Predicting E-tail Quality," Journal of Retailing, Vol.79, No.3, pp.183-198, 2003.

[35] Yoo, B., and Donthu, N. "Developing a Scale to Measure the Perceived Quality of an Internet Shopping Site (SITEQUAL)," Quarterly Journal of Electronic Commerce, Vol.2, No.1, pp.31-45, 2001.

[36] Yoon, S-J. "The Antecedents and Consequences of Trust in Online-Purchase Decisions," Journal of Interactive Marketing, Vol.16, No.2, pp.47-63, 2002.

[37] Zeithamal,V., Parasuraman, A., andMalhotra, A. "Service Quality Delivery through Web Sites: A Critical Review of Extant Knowledge," Journal of the Academy of Marketing Science, Vol.30, No.4, pp.362-375, 2002.

[38] Zeithamal,V., Parasuraman, A., andMalhotra, A., "A Conceptual Framework for Understanding e-Service Quality: Implications for Future Research and Managerial Practice," working paper, report No.00-115, Marketing Science Institute, Cambridge, MA., 2000.

\section{강 소 라(Sora Kang)}

[정회원]

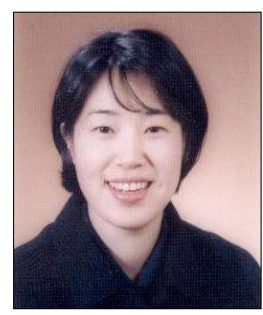

- 1994년 8월 : 이화여자대학교 대 학원 경영학과 (경영학석사)

- 2004년 2월 : 이화여자대학교 대 학원 경영학과 (경영학박사)

- 2006년 3월 현재 : 호서대학 교 디지털비즈니스학부 교수

<관심분야>

정보기술의 채택과 성과, 조직정치와 지식경영, $\mathrm{GSS}$, 그 리고 개인과 조직의 $\mathrm{UCC}$ 활용 등

\section{김 유 정(Yoo Jung Kim)}

[정회원]

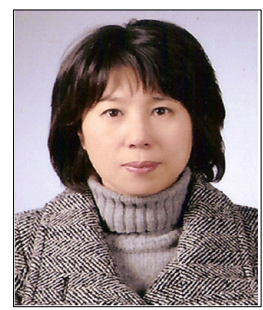

- 1999년 2월 : 고려대학교 경영학 과 MIS전공 (경영학박사)

- 2006년 3월 현재 : 호서대학 교 디지털비즈니스학부 교수

<관심분야>

융복합 인터넷 서비스, 정보시스템 평가, Web2.0 콘텐츠 (UCC) 이용과 확산 
이 현 주(HyunJu Lee)

[정회원]

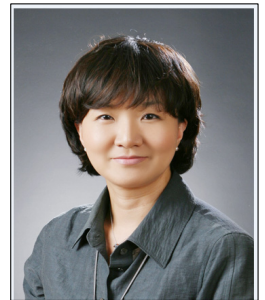

- 1989 8월 : Katz Graduate School of Business, University of Pittsburgh(MBA)

- 2007 2월 : 이화여자대학교 경영 학과 MIS전공(경영학박사)

- 2007년 7월 현재 : 호서대학 교산학협력단 전임연구원

<관심분야>

지식경영, 디지털비즈니스 경영전략, 경영혁신, Web2.0, 의료정보, $\mathrm{EDC}$ 시스템

문 윤 지(Yoon Ji Moon)

[정회원]

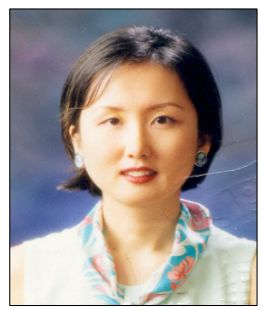

- 2004년 8월 : 이화여자대학교 대 학원 경영학과 (경영학석사)

- 2007년 2월 : 이화여자대학교 대 학원 경영학과 (경영학박사)

- 2007년 7월 현재 : 호서대학 교산학협력단 박사연구원

<관심분야>

정보기술의 채택과 성과, 지식경영, 경영혁신과 정보 기 술, 그리고 개인과 조직의 $\mathrm{UCC}$ 활용 등

김 우 곤(Woody Kim)

[정회원]

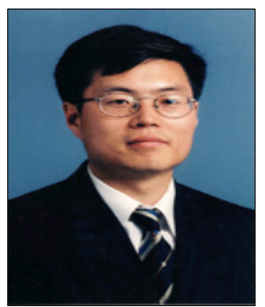

- 1988년 : University of Houston, 경영학 석사 (회계전공)

- 1990년 : University of Massachusetts, 호텔경영학 석사 (재무전공)

- 1995년 : Purdue University, 호 텔경영학 박사 (재무전공)

- 현재 : Florida State University, Dedman School of Hospitality,

<관심분야> 부교수

고객관계관리, 호텔 웹사이트 성공요인, 리스크 관리, 호 텔 경영 및 UCC 사용 등 